\title{
Yasmine Chami, Cerimonia
}

\section{Ilaria Vitali}

\section{(2) OpenEdition}

\section{Journals}

\section{Edizione digitale}

URL: http://journals.openedition.org/studifrancesi/33887

DOI: 10.4000/studifrancesi.33887

ISSN: 2427-5856

\section{Editore}

Rosenberg \& Sellier

\section{Edizione cartacea}

Data di pubblicazione: 1 décembre 2005

Paginazione: 692-693

ISSN: 0039-2944

\section{Notizia bibliografica digitale}

Ilaria Vitali, «Yasmine Chami, Cerimonia», Studi Francesi [Online], 147 (XLX | III) | 2005, online dal 30 novembre 2015, consultato il 19 avril 2021. URL: http://journals.openedition.org/studifrancesi/33887 ; DOI: https://doi.org/10.4000/studifrancesi.33887

\section{Questo documento è stato generato automaticamente il 19 avril 2021.}

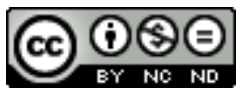

Studi Francesi è distribuita con Licenza Creative Commons Attribuzione - Non commerciale - Non opere derivate 4.0 Internazionale. 


\section{Yasmine Chami, Cerimonia}

Ilaria Vitali 


\section{NOTIZIA}

YASMINE CHAMI, Cerimonia, traduzione di Gabriella MESSI, Torino, Il leone verde, 2003, pp. 108.

1 I preparativi per le nozze di un membro della famiglia sono l'occasione per raccontare gli intrecci di una saga familiare attraverso le voci di due donne, unite nell'infanzia, separate da un destino diverso. Due cugine, Khadija e Malika, si ritrovano dopo anni di separazione, specchiandosi l'una nell'altra in una rivisitazione limpida del passato. La prima vive in Marocco, e, dopo un tormentato divorzio, è costretta a fare ritorno nella casa paterna; la seconda ha studiato e vive a Parigi, ha avuto successo, ha fatto un matrimonio d'amore, senza riuscire tuttavia ad avere figli. Attraverso le loro diversità, le due donne ritrovano le emozioni dell'infanzia e della prima giovinezza, di un passato al tempo stesso amato e odiato, vissuto nella grande casa di Fes, all'ombra del nespolo. La narrazione procede per flash-back, monologhi intrecciati e racconti nel racconto, come la storia della mula bianca, che sembra rispecchiare, come una mise en abyme, l'intero romanzo, fornendone allo stesso tempo la chiave di lettura. Lo stile poetico e raffinato dell'autrice coinvolge il lettore in una scrittura che abbraccia i cinque sensi, superando la sterile testimonianza sulla condizione femminile.

2 Autentica cerimonia, il romanzo vuole celebrare un tempo passato, circolare, a cui se n'è sostituito uno nuovo, quello della modernità, che procede in linea retta senza aver ancora definito i suoi nuovi riti. Scritta in un momento d'importante svolta nella realtà del Marocco, l'opera si concentra su un momento di passaggio, vissuto, anch'esso, come una cerimonia. Un romanzo tutto al femminile per dipingere in modo brillante e preciso un affresco della vita marocchina, superando i pregiudizi sulla religione islamica e gli stereotipi sulla condizione della donna che troppo spesso accompagnano lo sguardo occidentale nella lettura di autrici magrebine. 